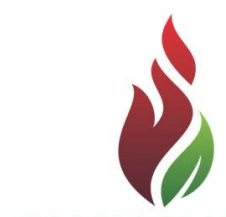

SUSTENERE

Publishing Corporation
REVISTA BRASILEIRA DE ADMINISTRAÇĀO CIENTIFICA

Journals Homepage:

www.sustenere.co/journals

\section{TRANSPARÊNCIA PÚBLICA MUNICIPAL: ANÁLISE DOS MUNICÍPIOS MARANHENSES POR MEIO DE SEUS WEBSITES OFICIAIS}

\section{RESUMO}

A transparência pública municipal tem sido tema de diversas análises com base nos elementos da Lei de Responsabilidade Fiscal (LC 101/2000). No entanto, essas discussões, em âmbito mais restrito, como o municipal, ainda não abarcam todo o território nacional. Buscou-se, neste estudo, conhecer o nível de transparência pública apresentada pelos munícipios maranhenses baseado em elementos orçamentários previstos na Lei de Responsabilidade Fiscal. A pesquisa foi realizada a partir de informações contidas nos websites dos municípios maranhenses, principal fonte de dados do estudo, cuja consulta deu-se entre os meses de março e abril de 2014. Os resultados demonstram que $75,12 \%$ desses municípios têm website oficial, mas que este ainda não se configura como ferramenta de divulgação de gestão fiscal: apenas 7,14\% deles disponibilizam do Plano Plurianual 2014-2017, a Lei Orçamentária Anual e a Lei de Diretrizes Orçamentárias referentes aos anos de 2014 estão em somente 8,44\% dos websites, o Relatório de Gestão Fiscal e o Relatório Resumido de Execução Orçamentária estão presentes em $16,34 \%$ e $15,38 \%$, respectivamente; outras ferramentas de transparência gerencial como a estrutura administrativa, atribuição dos órgãos e apresentação dos responsáveis também não são elementos frequentes nos websites. Conclui-se que a transparência de dados fiscais e gerenciais ainda não se apresenta fortemente nos municípios maranhenses, nem mesmo com a imposição legal de fazê-lo.

PALAVRAS-CHAVES: Transparência Fiscal; Municípios Maranhenses; Transparência Municipal.

\section{PUBLIC TRANSPARENCY CITIES OF MARANHÃO THROUGH ITS OFFICIAL WEBSITES}

\section{ABSTRACT}

The municipal public transparency has been the subject of several analyzes based on elements of the Fiscal Responsibility Law (Law 101/2000). However, these discussions have not yet covered the entire national territory. This study aimed to acknowledge the level of public transparency presented by the cities of Maranhão, from the budget components provided in the Fiscal Responsibility Law. The research was conducted through websites from cities of Maranhão, which was the main source of data, and the data collecting occurred between the months of March and April 2014 . The results show that $75.12 \%$ of these cities have an official website, but this still does not qualify as a dissemination tool of fiscal management, not providing data as administrative structure and budget components. It is concluded that the transparency of fiscal data is not yet strongly present in cities of Maranhão, even this being a legal obligation.

KEYWORDS: Fiscal Transparency; Cities of Maranhão; Municipal Transparency.
Revista Brasileira de

Administração Científica,

Aquidabã, v.6, n.1, Jan, Fev, Mar,

Abr, Mai, Jun 2014.

ISSN 2179-684X

SECTION: Articles

TOPIC: Gestão Pública

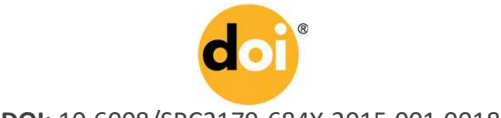

DOI: 10.6008/SPC2179-684X.2015.001.0018

Maria Rosivalda da Silva Pereira Universidade Federal do Maranhão, Brasil http://lattes.cnpq.br/2343986975821351 rosivaldapereira@uol.com.br

Daniel Arruda Coronel

Universidade Federal de Santa Maria, Brasil http://lattes.cnpq.br/9265604274170933 daniel.coronel@uol.com.br

Received: $14 / 01 / 2014$

Approved: 14/10/2015

Reviewed anonymously in the process of blind peer.

Referencing this:

PEREIRA, M. R. S.; CORONEL, D. A.. Transparência pública municipal: análise dos municípios maranhenses por meio de seus websites oficiais. Revista Brasileira de Administração Científica, Aquidabã, v.6, n.1, p.281295, 2015. DOI: http://dx.doi.org/10.6008/SPC2179$\underline{684 X .2015 .001 .0018}$ 


\section{INTRODUÇÃO}

A transparência dos gastos públicos, além de ser uma legítima preocupação social, tem sido objeto de discussão no âmbito acadêmico (CRUZ et al., 2012; NUNES et al., 2013; SOUZA et al., 2013). Tal preocupação se constitui um pressuposto da participação popular na gestão pública, através dos mecanismos facultados pela legislação brasileira, principalmente a partir da Lei de Responsabilidade Fiscal (Lei Complementar - LC n 101/2000, e Lei Complementar n 131 de 2009).

Até a promulgação dessas leis, os gastos públicos tinham seu controle exercido somente pelos órgãos oficiais de controle interno e externo, permitindo à sociedade fazê-lo de forma indireta por meio de seus representantes eleitos. A partir da LC 131/2009 os portais eletrônicos institucionais foram definidos também como canal par a publicação dos gastos públicos, ampliando a sua divulgação. Para que todos os entes federados pudessem ter tempo para se adequarem a essa nova perspectiva de transparência, fora dado prazo de implementação dos portais eletrônicos de forma diferenciada aos entes federados, conforme a sua estrutura: a União, os Estados e os Municípios com mais de cem mil habitantes tiveram até maio de 2010 para se adequarem; os municípios com população entre cinquenta e cem mil habitantes, até maio de 2011; já os municípios com menos de cinquenta mil habitantes tiveram prazo maior para cumprir tal exigência - maio de 2013.

No entanto, estudos tanto de abrangência nacional como regional apontam que esse marco legal não foi suficiente para que os entes federados tenham uma gestão transparente, pois nem todos os municípios atingem os requisitos mínimos exigidos pela legislação, independente de qual região o municípios faz parte (CRUZ et al., 2012; NUNES et al., 2013; SOUZA et al., 2013; STAROSCKY et al., 2014). Neste contexto, buscou-se conhecer a realidade em que se encontram os municípios do Estado do Maranhão, através da seguinte questão: os municípios maranhenses atendem aos requisitos de transparência preconizados na Lei de Responsabilidade Fiscal (LC 101/2000)?

O estado do Maranhão, de acordo com a Associação Contas Abertas (2012), é apresentado como um dos menos transparentes do país. No ranking divulgado em 2012, alcançou a décima sétima posição de transparência, enquanto que, no ano de 2010, ocupava a nona posição. O ranking é composto pela usabilidade do website, conteúdo, atualização histórica e frequência de atualização. O item, para esse estado, que recebeu a pior nota, foi o conteúdo do website, que obteve apenas $37,3 \%$ do total da nota possível para o item. Como esse índice, até o ano de 2012, analisava apenas os dados das contas estaduais, encontra-se a necessidade de conhecer a realidade de transparência em que se encontram os municípios desse estado.

Estudos dessa natureza caracterizam-se como de relevância social, pois pretendem demonstrar a realidade em que se encontra a transparência pública na região analisada e, assim, contribuir com uma gestão transparente e planejada consoante com aos anseios sociais. 
Além desta introdução, este artigo está estruturado da seguinte forma: na seção dois, demonstram-se resultados de estudos sobre a transparência municipal em diversas regiões brasileiras; na sequência, apresenta-se a metodologia usada para a realização deste estudo; a seção quatro é dedicada aos resultados e discussões, e, por fim, têm-se as conclusões encontradas.

\section{REVISÃO TEÓRICA}

\section{Transparência Pública: Evidências Empíricas}

Após a vigência da LC 101/2000 e da LC 131/2009, o tema transparência pública municipal tornou-se mais forte nos debates acadêmicos e vários estudos foram desenvolvidos para analisar se os entes públicos adequaram-se às exigências legais impostas por tais instrumentos, sobre a ótica da transparência pública. A transparência pública pode ser compreendida como algo que pressupõe a publicidade, a compreensibilidade e a utilidade para decisões. A publicidade é representada pela divulgação das informações de forma tempestiva, seguindo os pressupostos legais. A compreensibilidade abrange a forma de apresentação das informações para torná-las acessíveis a todos que tenham interesse nela. A utilidade para a tomada de decisões é decorrente dos dois princípios anteriores elencados, e na relevância e confiabilidade das informações disponibilizadas (PLATT NETO et al., 2007).

Assim, a transparência pública pressupõe não apenas a publicitação de contas públicas e ações dos governos, mas também se constitui por informações claras e específicas sobre as responsabilidades da estrutura administrativa e das pessoas que a compõe, possibilitando que o cidadão conheça as atribuições dos órgãos e possa direcionar suas demandas ao órgão competente a resolvê-las, evitando trâmites desnecessários, que podem resultar em custos à administração pública e prejuízos ao cidadão. O conhecimento sobre o nível de transparência em cada esfera pública e das variáveis que contribuem para uma gestão mais transparente permite que o cidadão tenha mais elementos de controle, capazes de efetivamente modificar a realidade em que ele está inserido.

Ribeiro e Zuccolotto (2012) buscaram analisar quais fatores influenciam o nível de transparência fiscal eletrônica dos municípios brasileiros, com uma amostra de 1.710 municípios distribuídos proporcionalmente em todos os estados brasileiros. Os dados foram coletados a partir de um roteiro que incluiu os balanços, as prestações de contas ao controle externo, os processos de aquisição de bens e serviços e a estrutura mínima do website, a partir do qual foi elaborado um índice de desempenho da transparência municipal, categorizando os municípios em alto, médio e baixo, conforme o desempenho. Além disso, foram usadas também outras variáveis explicativas: IFDM-educação, IFDM - emprego e renda; IFDM- saúde; gasto com educação per capita; gasto com saúde per capita; receita orçamentária per capita. 
Foi encontrado que a maioria dos municípios pesquisados encontra-se com o índice médio de transparência $(71,58 \%)$ e apenas $8,48 \%$ encontra-se com um baixo nível de transparência, o que demonstra que a maioria dos municípios brasileiros ainda não tem uma gestão fiscal transparente e possível de ser compreendida pelo cidadão (RIBEIRO \& ZUCCOLOTTO, 2012). As variáveis que mais impactaram a transparência pública foram o IFDM-Saúde e IFDM-Educação. Assim, os municípios que têm melhores indicadores de saúde, educação e geração de emprego e renda apresentaram melhores níveis de transparência. Outro importante resultado foi que os municípios que têm maior arrecadação relativa são mais propensos a divulgarem suas informações em meio eletrônico, assim como aqueles que gastam mais com educação e saúde (RIBEIRO \& ZUCCOLOTTO, 2012).

Souza et al. (2013) buscaram identificar quais variáveis socioeconômicas tiveram influência sobre o nível de transparência das informações governamentais divulgadas via internet dos municípios de médio porte brasileiros, que, seguindo o critério utilizado pelo Instituto Brasileiro de Geografia e Estatística (IBGE), são aqueles que têm entre 100.000 e 500.000 habitantes. A região que abriga a maior quantidade de municípios com essa característica é a Sudeste $(50,21 \%)$ do país, e a que tem a menor quantidade deles é a região Centro-Oeste (5,35\%). A pesquisa foi feita usando um roteiro preestabelecido com itens sobre a gestão pública e variáveis socioeconômicas. As variáveis utilizadas para a realização desse estudo consideraram a filiação partidária do prefeito, a participação em redes de integração municipal (Mercociudades), a região do município, as despesas e receitas municipais, características dos domicílios, estabelecimentos comerciais e de saúde, emprego, renda e população alfabetizada (SOUZA et al., 2013).

O Índice de Transparência Municipal usado por Souza, Boina e Avelar (2013) apresenta-se da seguinte forma: conteúdo, série histórica, atualização e usabilidade. A série histórica e a frequência de atualização de dados apresentou a maior média entre todos os componentes do índice, com $56 \%$ de presença, seguida pela usabilidade do site. A análise realizada, em relação ao conteúdo do site, no que se refere aos dados orçamentários, teve uma média de $34,02 \%$ dos itens previamente estabelecidos; a receita orçamentária foi o item que teve maior média de apresentação entre os municípios analisados. De forma geral, os municípios analisados apresentaram um nível de $37,3 \%$ do que foi esperado para a transparência (SOUZA et al., 2013).

Apesar de, na pesquisa, a maior amostra ser proporcionalmente da Região Sudeste do país, pertencer a esta região não se mostrou influente para que esses municípios fossem mais ou menos transparentes, assim como o partido político do gestor maior. Já as variáveis que se referem ao desenvolvimento do município apresentam relações significativas com o nível de transparência apresentado bem como participar de uma rede de integração municipal (SOUZA et al., 2013). O resultado das variáveis que relacionam o desenvolvimento municipal como fator de influência sobre a transparência pública corroboram os resultados de Ribeiro e Zuccolotto (2012).

As análises de Cruz et al. (2012) abordaram a transparência em grandes municípios brasileiros por meio de seus portais eletrônicos. Para tanto, foram elaborados indicadores para 
construir um índice de transparência da gestão pública municipal, elaborado a partir de códigos internacionais de boas práticas de transparência e governança e da legislação brasileira pertinente ao assunto. Além de dados sobre a gestão fiscal, foram inseridas variáveis socioeconômicas.

O objeto de análise foi o próprio website dos municípios de onde foram retirados os dados para a construção do índice. Tais informações basearam-se em dados gerais sobre o município, seu gestor, a legislação municipal e os instrumentos de planejamento, as informações financeiras disponíveis, a interação com o cidadão e dados sobre a gestão municipal. Também foram inseridos indicadores socioeconômicos como renda per capita, taxa de alfabetização, potencial de consumo, dentre outras. Os dados foram analisados por meio de regressão linear e análise de clusters (CRUZ et al., 2012).

Foi observado que aqueles municípios não têm um bom índice de transparência, seguindo o modelo estimado, uma vez que não divulgam as informações a contento, de acordo com o modelo utilizado; e que o nível de transparência apresentado é incompatível com o seu desenvolvimento econômico, visto que foi encontrado entre os municípios com maior participação no Produto Interno Bruto brasileiro, índice considerado com uma baixa média - a média encontrada na análise foi abaixo de $50 \%$ do que foi estimado como nota máxima encontrada. Destaca-se que esses municípios têm a obrigação de divulgar as informações sobre os atos de sua gestão desde maio de 2001, por se tratarem de municípios com população acima de 100.000 habitantes.

Os maiores índices de transparência foram encontrados nos municípios que apresentam também melhores indicadores socioeconômicos, o que corrobora os resultados de Ribeiro e Zuccolotto (2012) e de Souza, Boina e Avelar (2012). Dentre esses municípios, inserem-se as capitais brasileiras, e os demais municípios estão mais concentrados nas regiões Sul e Sudeste do país, uma vez que há mais municípios com maior população nessas regiões (CRUZ et al., 2012). Em um contexto mais restrito, Staroscky et al. (2014) utilizaram a metodologia Multicritério de Apoio a Decisão - Construtivista (MCDA-C) para analisar o nível de transparência em nove municípios catarinenses atendidos pela Secretaria de Desenvolvimento Regional de Chapecó, entre maio e julho do ano de 2013. Para tanto, foi criada uma escala que varia de -50 a 150 , a qual caracteriza o nível de divulgação das peças orçamentárias desses municípios, que seriam classificados em cinco níveis de impacto (N1 a N5, em que N5 seria o melhor nível alcançado). Atingem o nível de excelência os municípios que obtêm acima de 100 pontos.

$\mathrm{Na}$ avaliação global dos municípios, metade deles não atinge o $\mathrm{N} 2$, que seria correspondente ao nível neutro de transparência (divulgar minimamente o PPA, a LDO e a LOA e seus anexos e mais a legislação municipal); o esperado era que os municípios ficassem entre o nível neutro e o bom. Os autores encontraram que esses municípios ainda não se adaptaram aos requisitos de transparência pública, não disponibilizando informações já constantes nas leis de 
responsabilidade fiscal e de transparência pública (LC 101/2000 e 131/2009), como as peças orçamentárias e informações sobre o os servidores, por exemplo (STAROSCKY et al., 2014).

O conteúdo informacional analisado nos websites apontou que os procedimentos licitatórios e dados sobre os concursos públicos foram os itens mais transparentes, entre os analisados, e o perfil organizacional (estrutura), os dados referentes aos recursos humanos, convênios e diárias foram os menos transparentes. Em relação à usabilidade, as seções de perguntas, acesso e pesquisa foram as que obtiveram menor nota, sugerindo que a comunicação com a sociedade não é facilitada, assim como a disponibilidade de séries históricas de informações sobre o município e a autenticidade das informações (STAROSCKY et al., 2014).

A transparência pública em municípios com mais de 50.000 habitantes do estado do Rio Grande do Norte foi objeto de investigação por Souza et al. ( (2013). A pesquisa construiu um ranking de transparência municipal, composto por itens que revelam a divulgação de informações sobre as contas públicas, recursos humanos, atualização de dados e série histórica e a usabilidade do site; a pesquisa buscou também identificar se os níveis de transparências encontrados teriam alguma relação com indicadores sociais e econômicos dos municípios. As variáveis utilizadas foram o "Índice de Desenvolvimento da Educação Básica do $5^{\circ}$ ao $9^{\circ}$ ano de 2012, o Índice de Desenvolvimento Humano para o ano de 2013, o PIB per capita para o ano de 2012, o Índice FIRJAN para o ano de 2012 e a Receita Tributária para o ano de 2012" (SOUZA et al 2013, p.106). A amostra foi composta por oito municípios.

Os resultados demonstram que, em relação ao conteúdo disponibilizado no website, o detalhamento com pessoal obteve menor índice em todos os municípios analisados, seguido pela receita orçamentária, enquanto que a classificação orçamentária obteve o melhor índice de presença nos municípios. Sobre a série histórica e atualização de dados, foi observado que os municípios apresentam os dados sobre a execução orçamentária de forma tempestiva em todos os websites; os dados históricos, no entanto, apesar de presentes em todos os portais são disponibilizados apenas dados de períodos recentes (a maioria, dos últimos três anos). Com relação aos indicadores socioeconômicos, foi encontrada uma relação positiva entre eles e o nível de transparência encontrado nos municípios (SOUZA et al., 2013).

O ranking elaborado apontou que o município de Natal, capital do estado, apresentou o melhor índice entre os municípios analisados, sendo itens de maior pontuação o conteúdo, a série histórica e a atualização (este item alcançou a pontuação máxima). O pior índice foi apresentado pelo município de São Gonçalo do Amarante, cujo índice alcançou 59\% (SOUZA et al., 2013). Nunes et al. (2013) analisaram os instrumentos de transparência contidos da LRF nos municípios com população entre 50.000 e 100.000 habitantes, nos estados da Região Sul do Brasil. A partir do critério populacional, a pesquisa foi realizada em 51 municípios. A coleta de dados foi feita a partir de check-list composto pelos elementos consolidados da LC n 101/ 2000 e LC n 131/2009, que tratam de transparência fiscal. A análise foi realizada primeiramente por estado, e posteriormente, os dados foram reunidos para formar a retrato da Região Sul. 
Os municípios do Estado do Rio Grande do Sul não apresentaram todos os requisitos exigidos pela LC 101/2000. Houve município que apresentou até $96 \%$, não alcançando o máximo por não apresentar o lançamento de receitas (o que não foi apresentado por nenhum município desse Estado). Foi encontrado município que, além de disponibilizar poucos dados, o fez de forma intempestiva. Também foi identificado que as informações estavam divulgadas de forma dispersa no site, de modo a dificultar uma análise mais estruturada; no entanto, destaca-se que, para o uso dessas informações, não precisa ser efetivado cadastro, o que torna possível o acesso por qualquer pessoa. Os maiores índices de transparência encontrados também coincidiram com melhores indicadores de desenvolvimento (NUNES et al., 2013).

Sobre os municípios de Santa Catarina, quase metade deles atingiu mais que $75 \%$ de todos os requisitos estabelecidos pelo estudo; no entanto, um deles apresentou menos de $22 \%$ das informações, sendo estas limitadas somente ao que já era obrigatório antes da vigência da LC 101/2000. Em média, a apresentação das entidades que compõem a estrutura do município, juntamente com o valor da arrecadação foram os itens mais presentes nos resultados (NUNES et al., 2013). Para o estado do Paraná, 12 municípios encontram-se dentro do limite de habitantes objeto da pesquisa. O resultado apontou que apenas um dos municípios apresentou entre $25 \%$ e $50 \%$ dos requisitos do check-list; os demais apresentaram mais de $75 \%$ dos requisitos da pesquisa (NUNES et al., 2013).

Em suma, os municípios analisados na Região Sul não apresentam, em sua totalidades, os requisitos preestabelecidos na pesquisa de Nunes et al. (2013), que foram consolidados a partir do art. 48 da LC 101/2000 e alterações. O estado do Paraná teve a maior quantidade de municípios atendendo aos requisitos, enquanto que o de Santa Catarina teve a menor quantidade (66\% dos municípios desse estado apresentaram mais que $70 \%$ dos requisitos). Em comparação com o IDH-M, IFDM e IRFS, não foram encontradas relações diretas entre a transparência daqueles municípios e esses índices. Observou-se, pelos estudos apresentados, que os municípios das diversas regiões do país, independente de seu tamanho, e, portanto, do tempo que tiveram para adequarem-se às normas legais de transparência pública, ainda não apresentam níveis satisfatórios de informações que levem ao cidadão os mecanismos necessários para um melhor acompanhamento da gestão pública.

\section{METODOLOGIA}

Para responder à questão de pesquisa e ao objetivo proposto, utilizou-se o roteiro de avaliação utilizado por Prado (2004), por meio do qual se buscou identificar se o município mantém ou não website, e, em caso positivo, procurou-se identificar a forma utilizada para a comunicação com o cidadão; se apresenta a sua estrutura administrativa, o diário oficial do município; o serviço de busca interno; se o website apresenta os elementos de gestão fiscal, como a prestação de contas, orçamentos e se esses dados são de fácil acesso. Todos esses dados tiveram como fonte de pesquisa o próprio website do município. 
Os dados orçamentários foram considerados disponíveis quando foi possível acessar a íntegra dos documentos Plano Plurianual (PPA) 2014-2017, a Lei de Diretrizes Orçamentárias (LDO) e a Lei de Orçamento Anual (LOA) para o ano de 2014, bem como o Relatório Resumido de Execução Orçamentária (RREO) e Relatório de Gestão Fiscal (RGF) para o ano de 2013. A especificação desse período foi definida considerando que a maioria dos municípios maranhenses tem menos de 50.000 habitantes e somente em 2013 alcançaram a obrigação legal de divulgar as informações orçamentárias via internet. Por não ser objeto deste estudo a tempestividade na divulgação da informação, considerou-se o ano de 2013 para a divulgação dos instrumentos de prestação de contas, de forma a perceber se o município vem ou não cumprido a exigência legal de publicar suas informações fiscais obrigatórias.

Para apresentar o desenvolvimento socioeconômico dos municípios, acrescentou-se o Índice de Desenvolvimento Humano Municipal (IDHM) e a taxa de analfabetismo do município. Essas variáveis já foram utilizadas em outros estudos para relacionar o índice de transparência fiscal e o desenvolvimento do município (CRUZ et al. 2012). A fonte de dados para esses indicadores foi o Atlas de Desenvolvimento Humano no Brasil, elaborado pelo Programa das Nações Unidas para o Desenvolvimento (PNUD, 2013). A coleta de dados foi realizada nos meses de março e abril de 2014. Para identificar a existência ou não de website oficial do município, fezse uso de uma plataforma especializada em buscas na internet (Google $®$ ), usando o termo prefeitura do município [nome no município], e foram considerados websites oficiais aqueles que apresentaram a seguinte estrutura de domínio: 'www.nomedomunicipio.uf.gov.br' conforme utilizado na metodologia aplicada por Cruz et al. (2012).

Para os municípios inicialmente não localizados, foram realizadas novas tentativas de localização, em semanas alternadas, com vistas a sanar alguns problemas de indisponibilidade do portal. Da população de 217 municípios, a amostra ficou reduzida a 162 que dispunham de websites considerados oficiais no momento da pesquisa. A análise dos dados foi feita através de estatística descritiva, com o auxílio do software Microsoft $₫$ Excel 2010. Com exceção das variáveis socioeconômicas, as demais se tratavam de variáveis binárias para determinar a presença ou não do item no website, cuja análise foi feita distribuindo-se proporcionalmente a existência dos itens pesquisados entre os municípios, de forma a demonstrar a presença dos itens de transparência pública nos websites de prefeituras municipais maranhenses.

\section{RESULTADOS}

O estado do Maranhão possui uma população estimada em seis milhões e oitocentas mil pessoas, com extensão territorial de 331.937,150 km², distribuída em 217 municípios; sua densidade demográfica (hab/ $\mathrm{km}^{2}$ ) é de 19,81 e a renda per capita é de $\mathrm{R} \$ 360,34$, de acordo com a Pesquisa Nacional por Amostra de Domicílio (IBGE, 2012); em sua maioria, os municípios têm menos de 50.000 habitantes, conforme apresentado No Gráfico 1. 


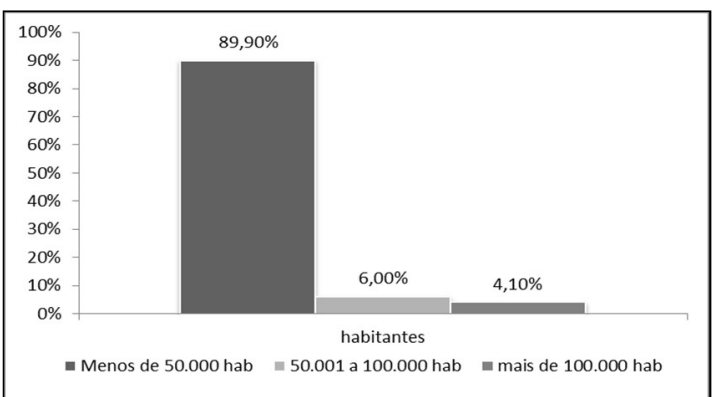

Gráfico 1: Municípios maranhenses, por número de habitantes.

Fonte: IBGE (2012).

O estado do Maranhão é composto, primordialmente, por municípios com menos de 50.000 habitantes, e, portanto, adquiriu a obrigação de disponibilizar os seus dados em portais específicos, via internet, em maio do ano de 2013. O desenvolvimento municipal no estado apresenta um nível baixo, conforme dados divulgado pelo PNUD (2013), seguindo os parâmetros o IDHM. A classificação dos municípios é demonstrada no Gráfico 2:

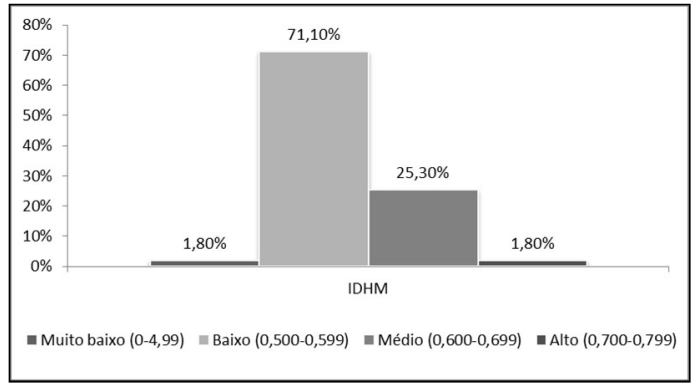

Gráfico 2: Distribuição IDH-M dos municípios maranhenses.

Fonte: PNUD (2013).

Observa-se que a maioria dos municípios maranhenses tem um IDHM considerado baixo $71 \%$, e apenas $25,3 \%$ apresentam um IDHM médio. Somente quatro municípios apresentam um IDHM em nível alto e quatro em nível muito baixo. Destaca-se que não houve registro de municípios neste estado com IDHM superior a 0,8, que corresponde a um nível muito alto. $O$ Índice de Desenvolvimento Humano do Estado é 0,639 (classificado como médio), e, em relação aos demais estados da federação, ocupa a penúltima posição no ranking nacional. $\mathrm{O}$ índice de analfabetismo no estado, entre os maiores de 15 anos de idade, é um dos mais altos do país; de acordo com o PNUD (2013), esse índice é de $20,8 \%$, sendo a quarta maior taxa de analfabetismo registrada no ano de 2010 para o Brasil. Em cerca de 46,6\% dos municípios maranhenses a população situada nessa faixa etária encontra-se com um índice de analfabetismo que varia entre 20 e $29,9 \%$ da população. Em 36,8\% municípios, quase um terço da população acima de 15 anos encontra-se analfabeta.

$\mathrm{Na}$ investigação sobre a disponibilidade ou não de portais eletrônicos, foi constatado que $24,88 \%$ dos municípios não o apresentam, e, dentre esses, um deles tem a obrigação de tê-lo desde maio de 2011; os demais são municípios com menos de cinquenta mil habitantes que deveriam ter se adequado em maio de 2013, o que ainda não aconteceu. Esse resultado não é 
muito diferente da análise feita por Wirght (2013), o qual retrata que $16,41 \%$ dos municípios brasileiros ainda não disponibilizam e, em termos regionais, o maior percentual encontrado foi na Região Nordeste, em que $32,80 \%$ dos municípios ainda não têm essa ferramenta.

Assim, apenas $71,42 \%$ dos municípios maranhenses dispõem de portal eletrônico na forma prefixada na legislação, seguindo o padrão 'www.nomedomunicipio.uf.gov.br'. Destaca-se, porém, que alguns desses municípios não colocam o seu nome completo no domínio, mas, mesmo assim, é possível encontrá-lo, pois utilizam a forma pela qual o município é mais conhecido. Foi constatado também que 3,70\% dos municípios maranhenses apresentam o domínio '.com', que não é coerente com a condição de ente governamental, e portanto, não foi considerado para este estudo. Para o estado do Paraná, esse domínio foi encontrado em cerca de $11,03 \%$ dos municípios, e os websites municipais com domínio .uf.gov.br correspondem a $86,47 \%$ nos municípios paranaenses, de acordo com a pesquisa de Franco et al. (2012).

$\mathrm{Na}$ análise dos websites municipais, em relação à forma de interação com a sociedade, buscou-se identificar se havia formas eletrônicas possíveis de serem usadas pela comunidade para se comunicar com os órgãos. Foi encontrado que 10,32\% dos municípios não dispõem de qualquer forma de contato eletrônico com a sociedade. Daqueles que apresentam canais de comunicação, o formulário foi o item mais presente (a pesquisa buscou identificar entre e-mail, formulário e chat). Para seu uso, não se encontrou restrições como solicitação de cadastro prévio, por exemplo. No entanto, trata-se de formulário que não apresenta recursos que permitam direcionar a mensagem para órgãos específicos do município. Ferramentas síncronas de comunicação, como o chat, não foram encontradas em nenhum dos websites investigados.

Sobre funcionalidades de navegação, como o 'mapa do site', constatou-se que não é comum nos portais eletrônicos dos municípios maranhenses; em apenas sete portais esse item foi encontrado. Nem mesmo a capital do Estado, que poderia servir de modelo para os demais municípios, não oferece essa ferramenta. A apresentação desse link permite uma melhor recuperação da informação buscada, uma vez que websites são espaços com fluxo dinâmico de conteúdo e, portanto, funcionalidades como esta contribuem para uma melhor interatividade.

Essas ferramentas podem ser consideradas como fontes de interação entre governo e sociedade, uma vez que facilitam a comunicação com o cidadão e possibilitam um melhor acesso à informação pública. Nos municípios maranhenses, mesmo quando realizados naqueles com maior número de habitantes, vão de encontro aos resultados encontrados por Cruz et al. (2010) em análise para os grandes municípios brasileiros, em que a maioria dos municípios apresentam 'mapa do site'. Outra questão analisada foi se a estrutura administrativa do município era divulgada, assim como as atribuições dos órgãos e os respectivos responsáveis. O resultado é apontado Gráfico 3, que segue. 


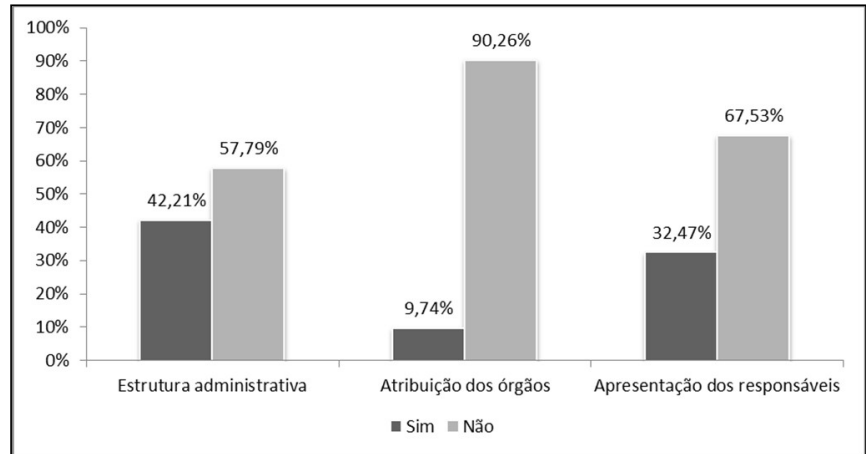

Gráfico 3: Apresentação da estrutura administrativa do município.

Dos três itens investigados, a estrutura administrativa é o item mais presente nos portais eletrônicos, mas sequer alcança metade dos municípios maranhenses. A atribuição dos órgãos é o item menos presente nos portais analisados, chegando a apenas $32,47 \%$ deles. Resultados similares foram encontrados em estudo realizado em municípios do estado de Santa Catarina, em que também a divulgação da estrutura do órgão não se encontrou presente naquela realidade (STAROSCKY et al., 2014). A não apresentação desses dados torna-se um obstáculo para que a sociedade realize qualquer fiscalização, uma vez que não dispõe de informações básicas que possam ser tidas como de referência, como, por exemplo, saber quais as secretarias existentes ou mesmo quem são os responsáveis por elas.

Tal informação pode ser corroborada com a ausência dos diários oficiais na internet, cujo objetivo é dar publicidade e legalidade aos atos de governo: apenas 9,09\% dos municípios maranhenses que têm website têm o seu diário oficial na internet. Destaca-se, no entanto, que os municípios têm autonomia para a criação ou não de diários oficiais; no entanto, deve eleger um canal oficial de comunicação com os cidadãos, de modo a dar ciência a todos dos atos de gestão - esse canal, ao que se percebeu, não é o website municipal.

Ao serem analisados os itens presentes no art. 48 da LRF, fica ainda mais difícil pensar em transparência pública nos municípios maranhenses. Neste contexto, buscou-se identificar se as peças orçamentárias vigentes no momento encontravam-se disponíveis (PPA, LOA, LDO, RREO, RGF). O Plano Plurianual 2014-2017 está presente apenas em 7,14\% dos portais municipais analisados; a Lei Orçamentária Anual e a Lei de Diretrizes Orçamentárias referentes ao ano de 2014 estão disponíveis em $8,44 \%$ dos portais. Simultaneamente, as três peças orçamentárias se apresentam em apenas 4,54\% desses municípios. Esses resultados vão ao encontro daqueles apresentados por Staroscky et al. (2014), em que o item "Peças orçamentárias" obteve baixa pontuação em todos os municípios analisados no estado, retratando a inexistência desses instrumentos de transparência e controle da sociedade nos websites das prefeituras catarinenses, e os de Franco et al. (2012), que nos municípios paranaenses encontraram que $88,22 \%$ deles não publicam suas peças orçamentárias. Ressalta-se que, no Maranhão, os municípios que mais apresentam simultaneamente todos as peças orçamentárias têm menos de 50.000 habitantes.

Em relação ao Relatório Resumido de Execução Orçamentária e o Relatório de Gestão Fiscal, buscou-se verificar a sua disponibilidade referente ao ano de 2013. Considerou-se como 
presente quando disponíveis aqueles relacionados a todo o período em questão. Observou-se a divulgação do RGF em apenas 16,34\% dos municípios e o RREO, em 15,58\% deles. Simultaneamente, eles são divulgados em formato eletrônico em apenas 13,63\% desses municípios. Realidade não muito diferente foi encontrada no Estado do Paraná, em que, na análise de Franco et al. (2012), apenas 11,53\% apresentam tanto o RREO quanto o RGF. Em síntese, a disponibilidade desses dados nos municípios maranhenses é apresentada no Gráfico 4, que segue:

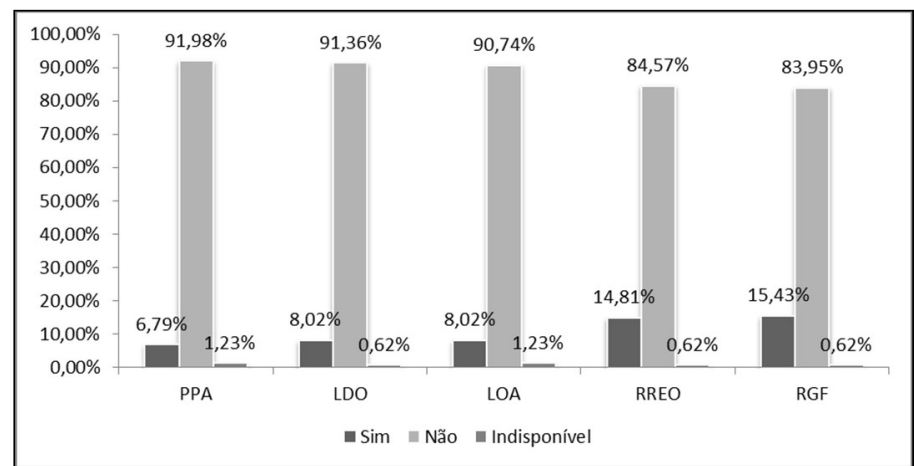

Gráfico 4: Disponibilidade dos dados de gestão fiscal dos municípios maranhenses.

Sobre a forma de localização das peças orçamentárias no website, buscou-se saber se havia a informação na página inicial deles e se havia a possibilidade de recuperação através dos serviços de pesquisa, quando disponíveis no website. Obteve-se que o link que poderia direcionar para a disponibilidade das peças orçamentárias está presente em $81,16 \%$ dos portais eletrônicos disponíveis. Mas, como já demonstrado, efetivamente ainda não são cumpridos tais regulamentos, uma vez que nem todos os websites disponibilizam esses dados. Platt Neto et al. (2007) caracterizam como falsa publicidade apontar um link para uma informação e este encontrar-se desativado; o ente público possibilita uma falsa expectativa de que cumpre os requisitos legais de transparência, mas efetivamente não o faz quando o conteúdo não é apresentado.

Dentre os portais que apresentam serviços de busca (36,36\%), em apenas $21,43 \%$ deles foi possível localizar pelo menos um dos itens de transparência fiscal: as peças orçamentárias, o relatório de gestão fiscal e o relatório resumido de execução orçamentária. A ausência constatada da ferramenta 'mapa do site' contribui para a não recuperação dessa informação nos websites. De maneira geral, a baixa disponibilidade de dados em websites municipais no Maranhão vai ao encontro dos resultados de Wright (2013), em que os municípios com menos de 50.000 habitantes apresentaram o menor nível de disponibilidades dessa ferramenta, e, por conseguinte, de informações sobre a sua gestão. Tendo o estado do Maranhão a maioria dos municípios com esse estrato populacional, já seria esperado encontrar esse resultado, que corrobora os resultado de Franco et al. (2012).

Cabe destacar também que a internet não se encontra presente em todos os domicílios maranhenses, o que, sem dúvida, pode colocar em cheque a proposta de transparência eletrônica 
no estado. De acordo com o IBGE (2012), essa ferramenta alcançava, no último censo, menos de $50 \%$ dos lares maranhenses, tendo inclusive registrado que, em três municípios maranhenses, não foram encontrados domicílios com computadores com acesso à internet. É importante destacar que o acesso à internet tem crescido através de outros equipamentos, como telefones celulares, por exemplo, mas que não se tem, no momento, estatísticas que possam informar o quantitativo de pessoas utilizam a internet por esse canal, no Maranhão.

Outra questão de destaque, é que a maioria dos municípios, conforme visto, apresentam IDHM baixo. Desses, o PPA presente em apenas $3,7 \%$ dos websites, e naqueles com IDHM médio, a presença é também é ínfima, estando em apenas 1,85\%. Com os demais itens, a realidade não se torna muito diferente. Tal resultado não pode causar surpresa, quando se encontra municípios em realidade de desenvolvimento humano baixo, taxas de analfabetismo altas entre a população com mais de 15 anos, justamente a faixa etária em que se encontram aqueles que têm o pleno direito ao exercício por meio do voto, e, portanto, o legítimo direito de fiscalização das ações públicas.

\section{CONCLUSÕES}

Este estudo teve por objetivo verificar a situação de transparência pública dos municípios maranhenses, com base na disponibilidade dos elementos previstos na Lei de Responsabilidade Fiscal, em seus websites oficiais. Observou-se que a maioria dos municípios maranhenses alcançou a obrigação de divulgar seus dados em website em maio de 2013. No entanto, somente $71,42 \%$ deles mantêm esse recurso de divulgação e transparência. Constatou-se, no entanto, que esse recurso ainda não é plenamente utilizado para a divulgação das informações pertinentes à gestão pública, tais como a divulgação do Plano Plurianual, da Lei de Diretrizes Orçamentárias e da Lei Orçamentária Anual. A prestação de contas anuais, o Relatório Resumido de Execução Orçamentária e o Relatório de Gestão Fiscal também se apresentam como itens raros nos websites dos municípios maranhenses. A mesma constatação é feita no tocante à divulgação da estrutura administrativa e apresentação de seus responsáveis. Dessa forma, os websites dos municípios maranhenses ainda não se firmaram como recurso de transparência e interação com a sociedade, ficando meramente como um mural de informações eletrônicas.

A realidade encontrada nos municípios maranhenses não difere dos estudos apresentados sobre a transparência municipal em outros estados e regiões brasileiras, o que leva a concluir que, mesmo após os municípios terem ciência do prazo da obrigação de fazer através da LC 131/2009, ainda não se adequaram. Pouco se sabe também sobre as penalidades legais/administrativas aplicadas aos municípios que não as cumprem. $O$ conhecimento tempestivo, por parte do cidadão, sobre os recursos disponíveis e empregados, e as ações que serão desenvolvidas a partir deles permite um melhor acompanhamento do real emprego dado 
aos gastos públicos e, consequentemente, se terá uma prestação de contas mais adequada, com serviços mais coerentes às necessidades dos municípios.

Assim, o cidadão maranhense ainda não dispõe de ferramentas efetivas que possam conduzir à transparência de gestão, como se supõe de uma realidade democrática, em que aqueles que gerem as cidades são representantes legitimamente eleitos. Neste estudo não se buscou esgotar as análises sobre a transparência pública no estado do Maranhão, inclusive por não haver estudos anteriores desenvolvidos nesta mesma realidade que possam ser comparados a este. Sugere-se que, em estudos futuros, possam ser feitas análises de cunho qualitativo para que a real dimensão dos dados disponibilizados nos websites municipais possa ser identificada como instrumento de transparência pública e de gestão, principalmente sobre a tempestividade e efetiva clareza dos dados apresentados.

\section{REFERÊNCIAS}

BRASIL. Lei Complementar $n^{\circ}$ 101, de 4 de maio de 2000. Estabelece normas de finanças públicas voltadas para a responsabilidade na gestão fiscal e dá outras providências. Brasília, 4 Mai 200.

BRASIL. Lei Complementar n 131, de 27 de maio de 2009. Acrescenta dispositivos à Lei Complementar no 101 , de 4 de maio de 2000, que estabelece normas de finanças públicas voltadas para a responsabilidade na gestão fiscal e dá outras providências, a fim de determinar a disponibilização, em tempo real, de informações pormenorizadas sobre a execução orçamentária e financeira da União, dos Estados, do Distrito Federal e dos Municípios. Brasília, 27 Mai 2009.

\section{COMITÊ GESTOR DA INTERNET. Resolução CGI.br/RES/2008/P. 2008..}

CRUZ, C. F.; FERREIRA, A. C. de S.; SILVA, L. M.; MACEDO, M. A. S.. Transparência da gestão pública municipal: um estudo a partir dos portais eletrônicos dos maiores municípios brasileiros. RAP, Rio de Janeiro, v. 46, n.1, p.153-176, 2012. DOI: http://dx.doi.org/10.1590/S0034-76122012000100008 .

CRUZ, C. F. I.; FERREIRA, A. C. S.; SILVA, L. M.; MACEDO, M. A. S.. Transparência da gestão pública municipal: um estudo a partir dos portais eletrônicos dos maiores municípios brasileiros. In: ENCONTRO DE ADMINISTRAÇÃO PÚBLICA E GOVERNANÇA. Anais. Rio de Janeiro, 2010.

FRANCO, L. M. G. et al. Transparência na divulgação da contabilidade pública municipal paranaense no ambiente da internet. In: ENCONTRO DA ASSOCIAÇÃO NACIONAL PÓS-GRADUAÇÃO E PESQUISA EM ADMINISTRAÇÃO, 36. Anais. Rio de Janeiro: UFRJ, 2012.

NUNES, G. S. D. F. et al. Análise dos instrumentos de transparências contidos na Lei de Responsabilidade Fiscal nos municípios da Região Sul. Revista Ambiente Contábil, Natal, v.5, n.2, p.128-150, 2013.

PLATT NETO, O. A.; CRUZ, F. da; ENSSLIN, S. R.; ENSSLIN, L.. Publicidade e transparência das contas públicas: obrigatoriedade e abrangência desses princípios na administração pública brasileira.

Contabilidade Vista e Revista, v.18, n.1, p.75-94, 2007.

PRADO, O.. Governo eletrônico e transparência: a publicização das contas públicas das capitais brasileiras. Dissertação (Mestrado em Administração) - Escola de Administração de Empresas de São Paulo da Fundação Getúlio Vargas, São Paulo, 2004.

RIBEIRO, C. P. D.; ZUCCOLOTTO, R. Fatores determinantes da transparência na gestão pública dos municípios brasileiros. In: ENCONTRO DE ADMINISTRAÇÃO PÚBLICA E GOVERNO. Anais. Salvador: UFBA, 2012.

SOUZA, A. A. D.; BOINA, T. M.; AVELAR, E. A.. Transparência na administração pública: uma análise das variáveis que influenciam a divulgaçaõ de informações por meio da internet nos municípios brasileiros de médio porte. In: SEMINÁRIOS EM ADMINISTRAÇÃO. 26. Anais. São Paulo, USP,2013. 
SOUZA, F. J. V. D.; BARROS, C. C.; ARAUJO, F. R.. Índice de transparência municipal: um estudo nos municípios mais populosos do Rio Grande do Norte. Revista de Gestão, Finanças e Contabilidade, Salvador, v.3, n.3, p.94-113, 2013.

STAROSCKY, E. A.; NUNES, G. S. F.; LYRIO, M. V. L.; LUNKES, R. J.. A transparência dos portais das prefeituras em municípios catarinenses sob a perspectiva da legislação brasileira. Reuna, Belo Horizonte, v. 19, n.1, p 29-52, 2014.

WRIGHT, G. A.. Análise dos fatores determinantes da transparência fiscal ativa nos municípios brasileiros. Dissertação (Mestrado) - Universidade Federal da Paraíba, João Pessoa, 2013. 